\title{
Necrotizing fasciitis in an immunocompromised elderly woman
}

\author{
Ananda Ghosh MD ${ }^{1}$, Jennie Johnstone MD FRCPC ${ }^{1,2}$
}

\begin{abstract}
CASE PRESENTATION
An 85-year-old woman presented to hospital with a rapidly progressing erythema of the lower left leg. The patient was well until several hours before admission when she noted a small area of painful erythema on her left shin that progressed over $2 \mathrm{~h}$ to involve the entire leg below the knee. There had been no erythema noted earlier that day when her daughter bathed her. Her medical history was significant for hypertension, congestive heart failure, remote left total knee arthroplasty and a recent diagnosis of temporal arteritis for which $40 \mathrm{mg}$ of prednisone daily was perscribed. She had no recent travel history and no sick contacts.

On presentation, the patient appeared well, was not in distress and was hemodynamically stable with a heart rate of 80 beats $/ \mathrm{min}$, blood pressure of $120 / 60 \mathrm{mmHg}$ and a temperature of $36.7^{\circ} \mathrm{C}$. Her physical examination was remarkable for erythema over the anterior lower left leg, extending around the calf. There were no bullae. Although the leg was tender to palpation, the pain was not out of proportion with the area of erythema. There was no crepitus, and no ulcers or ports of entry were apparent. No regional lymphadenopathy was present. Examination of the left knee found no warmth, effusion or erythema, and there was complete and pain-free range of motion. The remainder of her physical examination was unremarkable.
\end{abstract}

Initial investigations revealed a hemoglobin level of $146 \mathrm{~g} / \mathrm{L}$, a leukocyte count of $6.5 \times 10^{9} / \mathrm{L}$, a platelet count of $146 \times 10^{9} / \mathrm{L}$ and a creatinine level of $51 \mu \mathrm{mol} / \mathrm{L}$. Venous Doppler ultrasound of the left leg showed no evidence of deep vein thrombosis. Blood cultures were obtained before the patient was started on empirical intravenous antibiotic therapy with cefazolin ( $1 \mathrm{~g}$ every $8 \mathrm{~h}$ ) and clindamycin (600 mg every $8 \mathrm{~h}$ ).

After $24 \mathrm{~h}$ of therapy, the erythema of the leg improved; however, severe foot pain developed in the absence of any erythema. She remained hemodynamically stable with a blood pressure of $140 / 80 \mathrm{mmHg}$ and a heart rate of 80 beats/min and remained afebrile with a temperature of $36.5^{\circ} \mathrm{C}$ but had a notable drop in her leukocyte count to $1.8 \times 10^{9} / \mathrm{L}$. Her creatine kinase level $(26 \mathrm{U} / \mathrm{L}$ ) was normal (normal $<150 \mathrm{U} / \mathrm{L}$ ). Due to the confusing clinical picture and in light of her immunocompromised status, antibiotic coverage was broadened by discontinuing cefazolin and starting piperacillin/tazobactam ( $4.5 \mathrm{~g}$ every $8 \mathrm{~h})$.

Approximately $36 \mathrm{~h}$ after admission, she acutely deteriorated, developing fever $\left(37.9^{\circ} \mathrm{C}\right)$, hypotension $(80 / 60 \mathrm{mmHg})$, a decreased level of consciousness, and worsened edema and erythema of the left leg extending above the knee with multiple small foci of necrosis. She required transfer to the intensive care unit for inotropic support. Vancomycin was added to the piperacillin/tazobactam and clindamycin, intravenous immunoglobulin was given, and an urgent orthopedic surgery consultation was obtained. A fascial biopsy was performed, which was sent for frozen section and culture. The biopsy was consistent with necrotizing fasciitis (NF) and the patient was taken to the operating room for urgent debridement, where an above-knee amputation was performed. Postoperatively, the patient experienced ongoing hypotension and a new area of erythema over the upper left thigh extending to the abdomen. The piperacillin/tazobactam was discontinued and meropenem was added. The next day, there was growth in the tissue culture from the fascial biopsy. What was the causative organism?

\begin{abstract}
Diagnosis
Culture of the tissue produced heavy growth of Serratia marcescens as the sole identified pathogen. It was sensitive to ciprofloxacin, gentamicin, and trimethoprim/sulfamethoxazole, while resistant to all penicillins and cephalosporins. Blood and urine cultures remained negative.

Postoperatively, the patient stabilized hemodynamically and was taken off inotropic support shortly after being started on meropenem. However, she continued to require intubation and was found to have additional areas of erythema above her amputation and on her abdomen. On review with her family, they declined further surgical exploration and debridement; the areas of erythema did not expand and she remained hemodynamically stable on meropenem. However, the patient developed additional nosocomial complications, including candidemia, and died after a 28-day admission to the intensive care unit.
\end{abstract}

\section{DISCUSSION}

NF is a relatively rare, but severe, soft tissue infection that spreads along fascial planes with associated inflammation and necrosis. Even with optimal treatment, the overall mortality rate is $15 \%$ to $20 \%$ (1). NF is typically classified based on the microbial source of infection: type I is due to polymicrobial infection, usually consisting of Grampositive cocci, Gram-negative bacilli and anaerobes; and type II is monomicrobial and caused by Group A streptococcus. However, other monomicrobial causes of NF have been reported. A review of the English literature revealed eight published cases of NF caused by $S$ marcescens as the sole pathogen.

$S$ marcescens is a Gram-negative bacillus and member of the Enterobacteriaceae family. It is a saprophytic bacterium that is ubiquitous in the environment; however, it can cause nosocomial infection, more commonly in immunocompromised patients. It has been implicated in a variety of infections, including pneumonia, urinary tract infections, endocarditis, meningitis and wound infection (2).

$S$ marcescens is typically resistant to $\beta$-lactams due to production of chromosomal AmpC cephalosporinase (2). Thus, antibiotic therapy for $S$ marcescens infections should include a carbapenem, a fluoroquinolone or an aminoglycoside. As in all cases of NF, prompt source control of the infection by aggressive surgical debridement is imperative (3).

We summarized the previously published cases with $\mathrm{S}$ marcescens as the sole pathogen responsible for NF (Table 1). Our presented case, along with review of previous cases, emphasizes the need for an increased index of suspicion for this less common but more resistant etiological agent of NF in specific circumstances. Seven of the nine cases occurred in hosts who were immunocompromised in some form. Of the cases in which infection did not subside, the majority did not receive a carbapenem, a fluoroquinolone or an aminoglycoside. Therefore, we suggest consideration of $S$ marcescens among patients with NF who are immunocompromised and experience progressive infection despite

${ }^{1}$ Department of Medicine; ${ }^{2}$ Institute for Infectious Diseases Research, Faculty of Health Sciences, McMaster University, Hamilton, Ontario Correspondence: Dr Jennie Johnstone, Department of Medicine, McMaster University, 3200 MDCL, 1280 Main Street West, Hamilton, Ontario

L8S 4L8. Telephone 905-525-9140 ext 22726, fax 905-389-5822, e-mail johnsj48@mcmaster.ca 
TABLE 1

Summary of previously published cases of necrotizing fasciitis caused solely by Serratia marcescens

\begin{tabular}{|c|c|c|c|c|c|}
\hline $\begin{array}{l}\text { Author (reference), } \\
\text { year }\end{array}$ & Age/sex & Site & Immune status & Antibiotics used & Outcome \\
\hline Rimailho et al (4), 1987 & 74/male & Right leg & Competent & Penicillin & Died \\
\hline $\begin{array}{l}\text { Bornstein et al (5), } \\
1992\end{array}$ & 37/female & $\begin{array}{l}\text { Right axilla and } \\
\text { breast }\end{array}$ & Competent & $\begin{array}{l}\text { Penicillin, vancomycin, ciprofloxacin, } \\
\text { amikacin }\end{array}$ & Died \\
\hline Zipper et al (6), 1996 & 55/female & Right ankle/leg & Compromised (diabetes mellitus) & Ceftizoxime, clindamycin & Recovered \\
\hline \multirow[t]{2}{*}{ Huang et al (7), 1999} & 40/male & Left foot & Compromised (prednisone) & Ceftazidime & Recovered \\
\hline & 73/male & Right leg & Compromised (prednisone) & Ciprofloxacin & Recovered \\
\hline $\begin{array}{l}\text { Liangpunsakul and } \\
\text { Pursell (8), } 2001\end{array}$ & 66/female & Left ankle/leg & Competent & Penicillin, clindamycin, ceftriaxone & Died \\
\hline $\begin{array}{l}\text { Dubberke et al (9), } \\
2002\end{array}$ & 35/male & Right arm & Compromised (chemotherapy) & $\begin{array}{l}\text { Vancomycin, cefepime, gentamicin, } \\
\text { imipenem, clindamycin, ciprofloxacin }\end{array}$ & Recovered \\
\hline $\begin{array}{l}\text { Bachmeyer et al (10), } \\
2004\end{array}$ & 49/male & Right leg & Compromised (chemotherapy) & Piperacillin/tazobactam, amikacin, & $\begin{array}{l}\text { Cellulitis and wound } \\
\text { recovered, but died of SCLC }\end{array}$ \\
\hline Curtis et al, (3) 2005 & $51 / \mathrm{male}$ & Left leg & Compromised (diabetes mellitus) & $\begin{array}{l}\text { Vancomycin, ciprofloxacin, clindamycin, } \\
\text { aztreonam }\end{array}$ & Died \\
\hline $\begin{array}{l}\text { Ghosh and Johnstone, } \\
2013\end{array}$ & 85/female & Left leg & Compromised (prednisone) & $\begin{array}{l}\text { Cefazolin, piperacillin/tazobactam, } \\
\text { meropenem }\end{array}$ & Died \\
\hline
\end{tabular}

SCLC Small cell lung cancer

broad-spectrum $\beta$-lactam or cephalosporin therapy and aggressive surgical debridement. One other case (3) reported fresh water exposure before infection, as did our patient, suggesting that this may be an important historical clue.

The present case also illustrates the importance of obtaining tissue cultures in establishing an etiological agent in NF.

\section{REFERENCES}

1. Anaya DA, McMahon K, Nathens AB, Sullivan SR, Foy H, Bulger E. Predictors of mortality and limb loss in necrotizing soft tissue infections. Arch Surg 2005;140:151-7.

2. Hejazi A, Falkiner FR. Serratia marcescens. J Med Microbiol 1997:46:903-12.

3. Curtis C, Chock S, Henderson T, Holman MJ. A fatal case of necrotizing fasciitis caused by Serratia marcescens. Am Surg 2005;71:228-30.

4. Rimailho A, Riou B, Richard C, Auzepy P. Fulminant necrotizing fasciitis and nonsteroidal anti-inflammatory drugs. J Infect Dis 1987;155:143-6.
5. Bornstein PF, Ditto AJ, Noskin AH. Serratia marcescens cellulitis in a patient on hemodialysis. Am J Nephrol 1992;12:374-6.

6. Zipper RP, Bustamante MA, Khatib R. Serratia marcescens: A single pathogen in necrotizing fasciitis. Clin Infect Dis 1996;23:648-9.

7. Huang JW, Fang CT, Hung KY, Hsueh PR, Chang SC, Tsai TJ. Necrotizing fasciitis caused by Serratia marcescens in two patients receiving corticosteroid therapy. J Formos Med Assoc 1999;98:851-4.

8. Liangpunsakul S, Pursell K. Community-acquired necrotizing fasciitis caused by Serratia marcescens: Case report and review. Eur J Microbiol Infect Dis 2001;20:509-21.

9. Dubberke ER, Razavi B, Johnson RM. Serratia marcescens necrotizing fasciitis in a bone marrow transplant patient. Infect Dis Clin Pract 2002;11:25-7.

10. Bachmeyer C, Sanguina M, Turc Y, Reynaert G, Blum L. Necrotizing fasciitis due to Serratia marcescens. Clin Exper Dermatol 2004;29:673-87. 


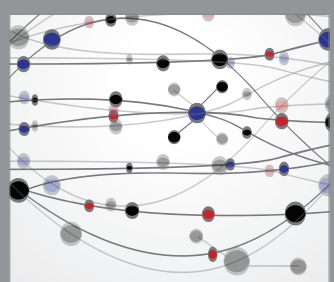

The Scientific World Journal
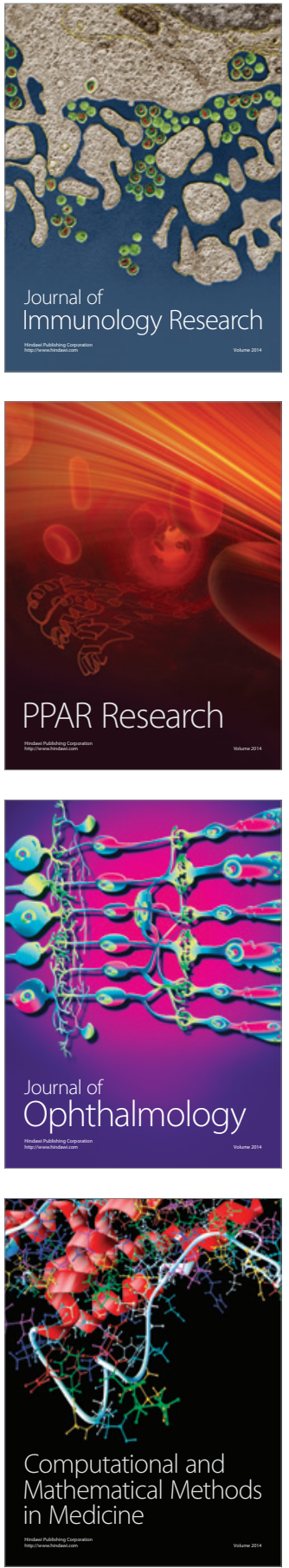

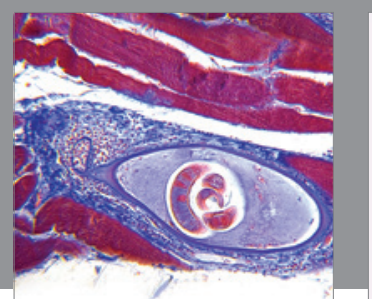

Gastroenterology Research and Practice

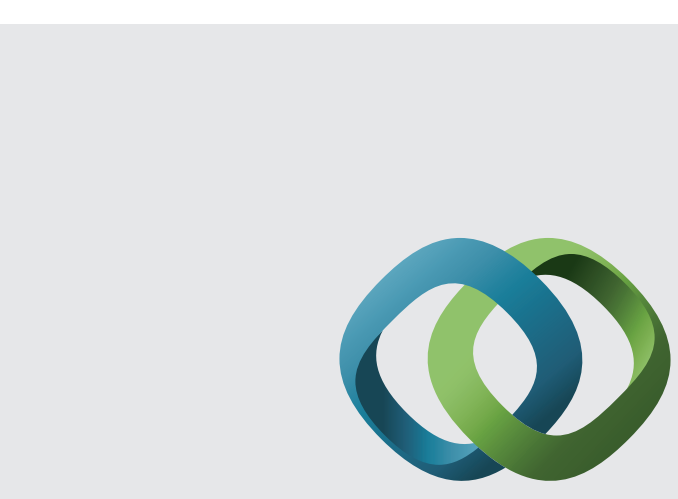

\section{Hindawi}

Submit your manuscripts at

http://www.hindawi.com
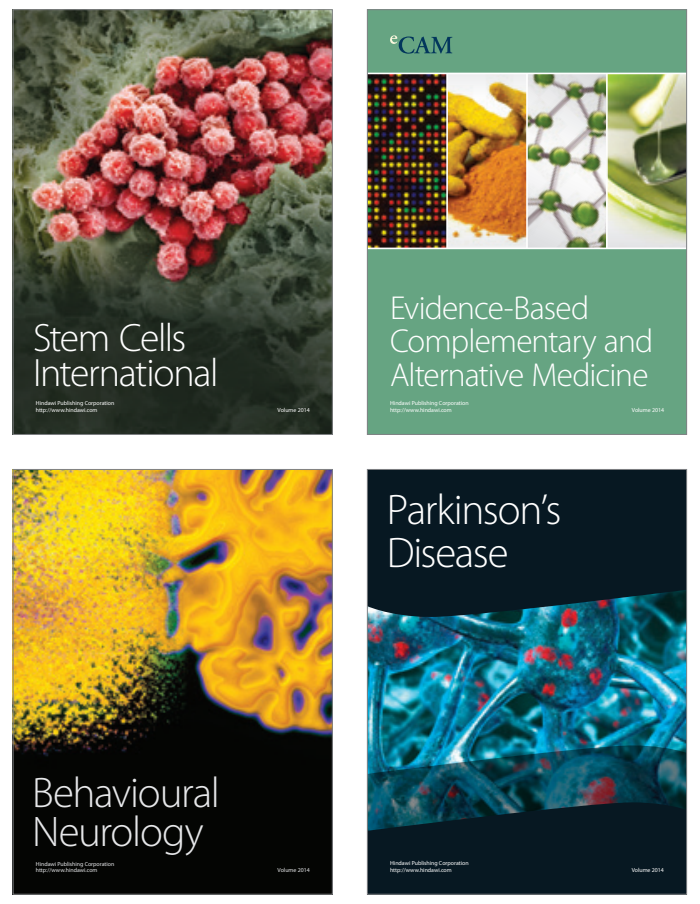
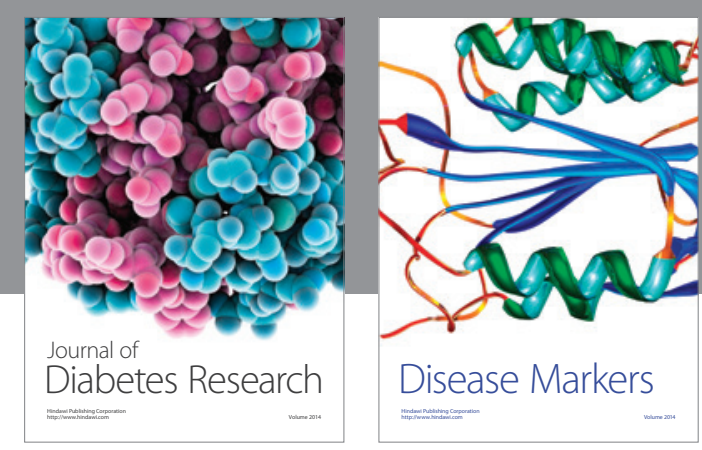

Disease Markers
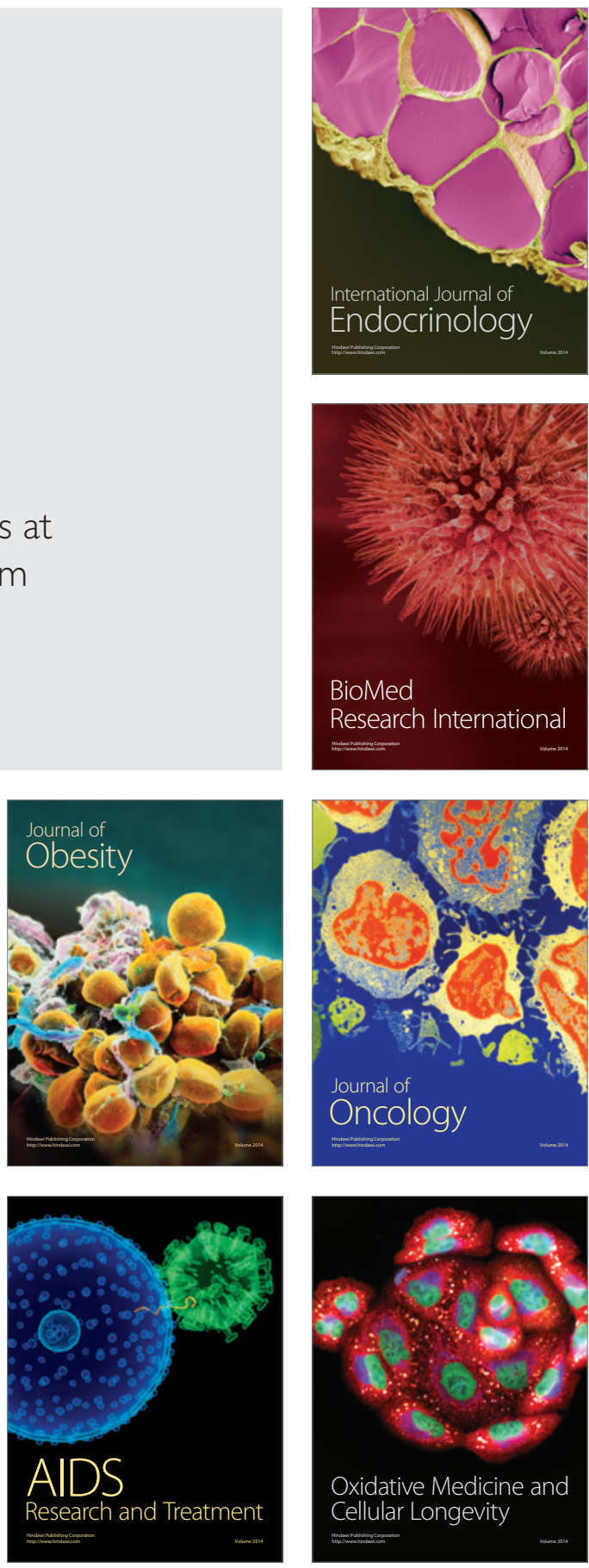